Article

\title{
Acetylene Abatement Over Micro/Mesoporous Active Carbon-Supported Low-Mercury Catalysts
}

\author{
Luo Jiang ${ }^{1}$, Ning Liu ${ }^{2} * * \mathbb{D}$, Chengna Dai ${ }^{2}$, Ruinian $\mathrm{Xu}^{2}{ }^{2}$, Biaohua Chen ${ }^{2}$ and Jirui Zhang ${ }^{3}$ \\ 1 State Key Laboratory of Chemical Resource Engineering, Beijing University of Chemical Technology, \\ Beijing 100029, China; jiangluo87@hotmail.com \\ 2 College of Environmental and Energy Engineering, Beijing University of Technology, Beijing 100124, China; \\ daicn@bjut.edu.cn (C.D.); xuruinian@bjut.edu.cn (R.X.); chenbh@bjut.edu.cn (B.C.) \\ 3 Beijing Huayutongfang Chemical Technology Development Co., Ltd., Beijing 100089, China; \\ zhangjirui36@hotmail.com \\ * Corresponding authors: liuning@bjut.edu.cn; Tel.: +86-10-67392430
}

Received: 12 November 2018; Accepted: 28 November 2018; Published: 3 December 2018

check for updates

\begin{abstract}
A series of low $\mathrm{HgCl}_{2}$-supported catalysts (K-TX-O, K-WG-O, K-S20-O, K-S40-O, K-Fe0.8-O, $\mathrm{K}-\mathrm{Fe} 0.8-\mathrm{M}, \mathrm{D}-\mathrm{Fe} 0.8-\mathrm{M})$ was prepared and investigated for $\mathrm{C}_{2} \mathrm{H}_{2}$ catalytic abatement during highly purified $\mathrm{HCl}(\mathrm{HP}-\mathrm{HCl})$ production process. The samples of D-Fe0.8-M, K-Fe0.8-M, and K-Fe0.8-O were found to exhibit much higher activities and better thermal stabilities than those of other samples. The characterization results of XRD, $\mathrm{N}_{2}$ adsorption/desorption, SEM, back scattered electron (BSE) and thermogravimetry (TG) revealed that: (i) the larger mesoporous volumes constituted one of the key factors leading to superior catalytic performances of D-Fe0.8-M, K-Fe0.8-M, and K-Fe0.8-O, which greatly facilitated better dispersions of the loaded $\mathrm{HgCl}_{2}$ species in comparison to other samples; (ii) the $\mathrm{KCl}$ additive could further improve the dispersions and thermal stabilities of the loaded the $\mathrm{HgCl}_{2}$ species due to the strong interactions between $\mathrm{KCl}$ and $\mathrm{HgCl}_{2}$ species, resulting in relatively higher catalytic behaviors of D-Fe0.8-M and K-Fe0.8-M than that of K-Fe0.8-O; (iii) the $\mathrm{KCl} / \mathrm{HgCl}_{2}$ step-by-step loading strategy, wherein the $\mathrm{KCl}$ was initially loaded on the Fe0.8-AC substrate thereafter followed by $\mathrm{HgCl}_{2}$ loading, could further improve the catalytic behavior for D-Fe0.8-M due to additional improvements of $\mathrm{HgCl}_{2}$ dispersions. The deactivation and reactivation of D-Fe0.8-M during $\mathrm{HP}-\mathrm{HCl}$ were also investigated, which suggested that partial deactivated D-Fe0.8- $\mathrm{M}$ by $\mathrm{C}_{2} \mathrm{H}_{3} \mathrm{Cl}$ accumulation could be efficiently reactivated by $\mathrm{HCl}$ treatment at $\mathrm{T}=220{ }^{\circ} \mathrm{C}$.
\end{abstract}

Keywords: low $\mathrm{HgCl}_{2}$-supported catalyst; active carbon (AC); $\mathrm{C}_{2} \mathrm{H}_{2}$ abatement; highly purified $\mathrm{HCl}$ $(\mathrm{HP}-\mathrm{HCl})$ production; $\mathrm{KCl}$ additive

\section{Introduction}

The highly purified hydrogen chloride $(\mathrm{HP}-\mathrm{HCl})$, functioning as one kind of micro-nano electron gas, has been widely utilized in the electronic chip production industry to etch and polish the $\mathrm{Si}$ wafer [1,2]. There are several approaches to produce $\mathrm{HP}-\mathrm{HCl}$ including direct $\mathrm{H}_{2}+\mathrm{Cl}_{2}$ reaction, $\mathrm{HCl}$ adsorption, and continuous rectification of the exhaust gas from the petrochemical industry, for example, trichloroethylene cracking, tetrachloroethylene cracking, and polyvinyl chloride production industries [3-7]. The latter two approaches have been widely applied in the practical productions of $\mathrm{HP}-\mathrm{HCl}$ due to huge amounts of low-cost $\mathrm{HCl}$ resource gases.

As for the continuous rectification approach, the impurity substance of hydrocarbon (HC), especially for acetylene, greatly influences the application of $\mathrm{HP}-\mathrm{HCl}$ as one kind of electron gas, due to that the HC impurity species could affect the electrical resistivity of the Si wafer [8-10]. Therefore, controlling the $\mathrm{HC}$ content constituted one of the most important jobs during $\mathrm{HP}-\mathrm{HCl}$ production 
from waste exhaust of the petrochemical industry. As reported [5,7], the HC impurity substances of trichloroethylene, tetrachloroethylene, dichloroethane and vinyl chloride can be readily separated by rectification approach. However, due to the close volatility the acetylene is hard to be separated from $\mathrm{HCl}$ by solely utilizing rectification approach.

Catalytic abatement of acetylene from $\mathrm{HCl}$ gases constituted a promising approach for the further purification of $\mathrm{HCl}$, among which the acetylene hydrochlorination generating vinyl chloride monomer (VCM) has been widely reported [11-15]. Hutchings and co-workers [16-18] have made great contributions on acetylene hydrochlorination and a series of metal chloride $(\mathrm{Au}, \mathrm{Bi}$ and $\mathrm{Pt})$ catalysts has been investigated [16,17], among which the Au-supported catalyst on activated carbon $(\mathrm{Au} / \mathrm{AC})$ [18] was reported to possess the highest activity. Recently, Oliver-Mess et al. [19] reported one type of Au nanoparticles (Au NPs) for hydrochlorination of alkynes, wherein the reaction occurred in a liquid phase and under a milder reaction conditions rather than those of gas phase proposed by Hutchings et al. [16-18]. However, although significant progress has been made for the Au-supported catalyst during acetylene hydrochlorination [20-22], the high cost constituted one of the biggest issues to be addressed during the practical application.

Recently, great efforts have also been made to explore the non-noble metal catalysts [11-15], among which the mercuric chloride $\left(\mathrm{HgCl}_{2}\right)$-supported on $\mathrm{AC}$, being widely utilized in acetylene hydrochlorination industry [23], is suitable for the catalytic abatement of acetylene during $\mathrm{HP}-\mathrm{HCl}$ production. However, the $\mathrm{HgCl}_{2}$ can easily volatilize from the substrate of $\mathrm{AC}$, resulting in irreversible deactivation and environmental pollutions. Therefore, lots of attention has been concentrated on the low-mercury catalysts [24-26], wherein the $\mathrm{CdCl}_{2}, \mathrm{CSCl}, \mathrm{BiCl}_{3}$ and $\mathrm{KCl}$ were utilized as the additives to reduce the amount of $\mathrm{HgCl}_{2}$ and also to improve the stability of the mercury catalyst. In addition to the active component, the substrate also played a key role in acetylene hydrochlorination. Dong et al. [27] utilizing one kind of mesoporous carbon as the substrate prepared S/N co-doped catalyst for acetylene hydrochlorination, which exhibited high acetylene conversion activity $(\sim 80 \%$ at $\mathrm{T}=220^{\circ} \mathrm{C}$ ). The mesoporous structure of the substrate was reported to greatly favor the acetylene hydrochlorination. According to the literature reports [28,29], the $\mathrm{Fe}_{3} \mathrm{O}_{4}$ could be utilized as one kind of additive to adjust the pore diameters of the active carbon (AC), especially generating mesoporous structures, which could thereby expand the $\mathrm{AC}$ applications. In light of that, present work would also utilize $\mathrm{Fe}_{3} \mathrm{O}_{4}$ as the additive to adjust pore structures for the AC substrate.

In present work, a series of AC-supported $\mathrm{HgCl}_{2}$ with low-mercury content (5.5 wt \%) was evaluated for acetylene catalytic abatement, wherein the substrates of $\mathrm{AC}$ were prepared by various approaches, including activation under different times, mixing with $\mathrm{Fe}_{3} \mathrm{O}_{4}$, and utilizing $\mathrm{KCl}$ as the additive. The physiochemical properties, catalytic activities, as well as stabilities of the prepared samples, were thereafter systematically investigated by X-ray diffraction (XRD), scanning electron microscope (SEM), Brunauer-Emmett-Teller (BET), thermogravimetry (TG) and activity measurements, respectively. The catalyst sample possessing highest acetylene conversation activity was thereafter obtained, which provides a promising candidate for $\mathrm{HP}-\mathrm{HCl}$ catalytic purification.

\section{Results and Discussion}

\subsection{Physicochemical Characterizations}

\subsubsection{BET}

Figure 1 displays the $\mathrm{N}_{2}$ adsorption/desorption profiles for the prepared samples of K-WG-O, K-TX-O, K-S20-O, K-S40-O, K-Fe0.8-O, K-Fe0.8-M and D-Fe0.8-M. According to Lowell et al. [30], (i) the isotherms of K-TX-O, K-WG-O and K-S20-O could be assigned to Type I, because the apparent hysteresis loops of these samples were all close at $\mathrm{p} / \mathrm{p}_{0}<0.4$; (ii) while for the samples of K-S40-O, $\mathrm{K}-\mathrm{Fe} 0.8-\mathrm{O}, \mathrm{K}-\mathrm{Fe} 0.8-\mathrm{M}$ and D-Fe0.8-M, the Type II isotherms could be clearly observed, wherein the gradual rise of volume adsorbed from $\mathrm{p} / \mathrm{p}_{0}=0.2$ to 0.9 was due to multilayer adsorption in significant external surface and mesopores. As noted, the Type I isotherms are characteristic of microporous 
materials, while the isotherms of Type II represent the materials containing both the micropores and mesopores. Therefore, it can be deduced that the samples of K-TX-O, K-WG-O and K-S20-O exhibiting largely Type I isotherm are indicative of microporous materials with little exterior surface area. On the contrary, K-S40-O, K-Fe0.8-O, K-Fe0.8-M, and D-Fe0.8-M have largely Type II isotherms, which are associated with mesoporous materials that have significant mesoporous surface areas. Figure $2 \mathrm{a}-\mathrm{g}$ further depict pore diameter distribution diagrams, which suggested that (i) the pore diameters of K-TX-O and K-WG-O were mainly located in the microporous range of $0-2 \mathrm{~nm}$; (ii) as for K-S20-O, the pore diameters were located at both the microporous and mesoporous ranges of $0-2 \mathrm{~nm}$ and $2-4 \mathrm{~nm}$; (iii) while for the samples of K-S40-O, K-Fe0.8-O, K-Fe0.8-M and D-Fe0.8-M, the related pore diameters were mainly located at $4-8 \mathrm{~nm}$. These findings were consistent with the results of derived from the $\mathrm{N}_{2}$ isotherms.

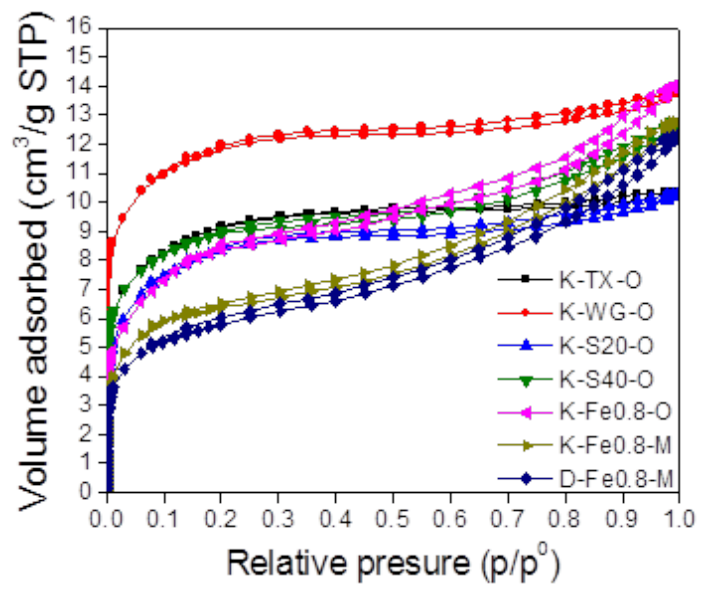

Figure 1. $\mathrm{N}_{2}$ adsorption/desorption profiles for the samples of K-TX-O, K-WG-O, K-S20-O, K-S40-O, K-Fe0.8-M, and K-Fe0.8-O.
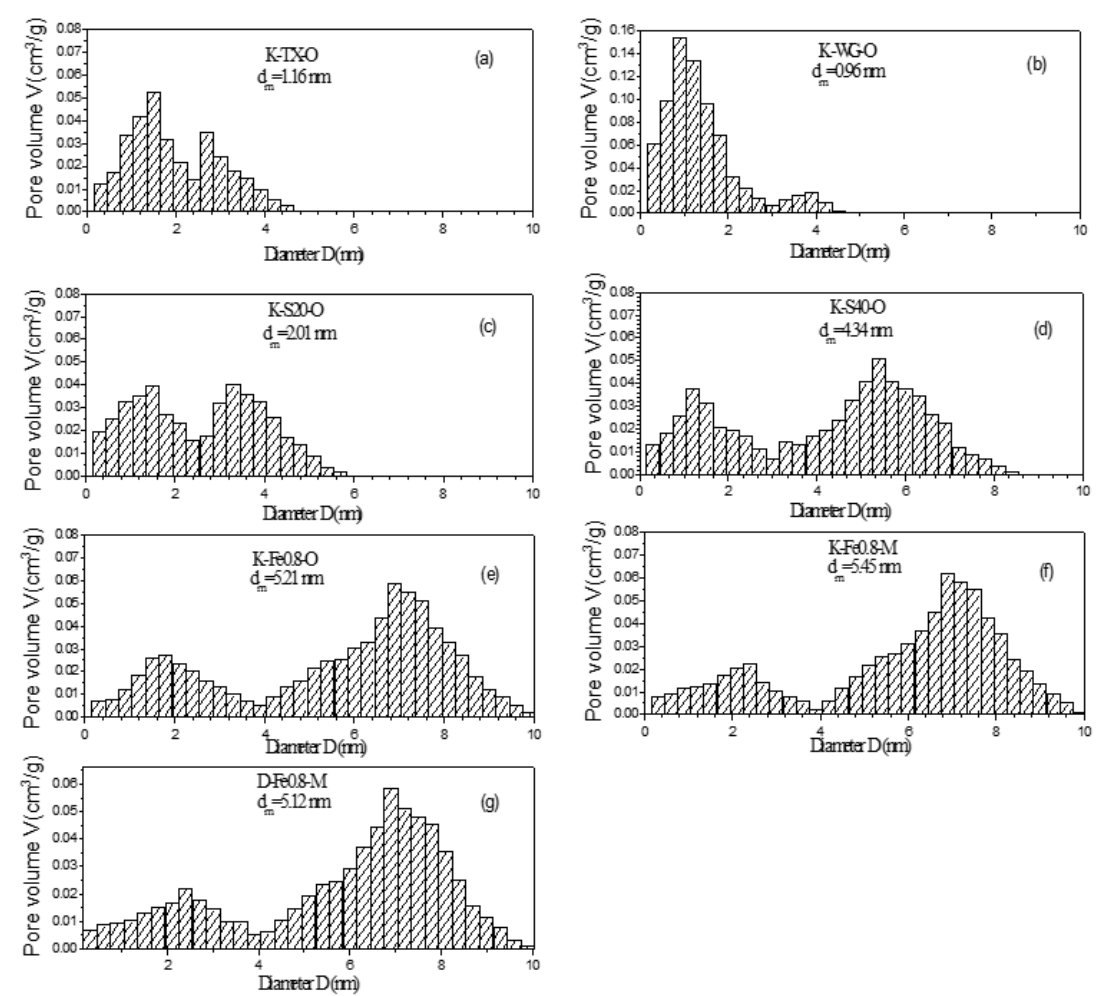

Figure 2. Pore diameter distributions for the samples of (a) K-TX-O, (b) K-WG-O, (c) K-S20-O, (d) $\mathrm{K}-\mathrm{S} 40-\mathrm{O}$, (e) K-Fe0.8-O, and (f) K-Fe0.8-M, derived from $\mathrm{N}_{2}$ adsorption/desorption. 
Table 1 further summaries the BET surface area $\left(\mathrm{S}_{\mathrm{BET}}\right)$, total pore volume $\left(\mathrm{V}_{\text {total }}\right)$, micropore volume $\left(\mathrm{V}_{\text {micro }}\right)$, mesopore volume $\left(\mathrm{V}_{\text {meso }}\right)$, mesopore volume ratio $\left[\mathrm{V}_{\text {meso }}\left(\mathrm{V}_{\text {total }}\right)^{-1}\right]$, and mean pore diameter (D) of the prepared low-mercury catalyst samples. It can be found that the values of $\mathrm{S}_{\mathrm{BET}}$ and $\mathrm{V}_{\text {total }}$ were slightly lower than those of the AC substrates listed in Table S2, which can be related to loading of $\mathrm{HgCl}_{2}$ species. Additionally, the samples of K-Fe0.8-O $\left(\mathrm{S}_{\mathrm{BET}}=2019 \mathrm{~m}^{2} \mathrm{~g}^{-1}\right)$ and K-WG-O $\left(\mathrm{S}_{\mathrm{BET}}=2137 \mathrm{~m}^{2} \mathrm{~g}^{-1}\right)$ possessed much higher $\mathrm{S}_{\mathrm{BET}}$ values than those of other catalysts, and the lowest value of $\mathrm{S}_{\mathrm{BET}}$ was observed for the sample of K-TX-O $\left(\mathrm{S}_{\mathrm{BET}}=1545 \mathrm{~m}^{2} \mathrm{~g}^{-1}\right)$. However, as noted herein, although the $\mathrm{S}_{\mathrm{BET}}$ of K-WG-O was higher than those of K-Fe0.8-O, K-Fe0.8-M and D-Fe0.8-M, the related $V_{\text {meso }}\left(0.35 \mathrm{~cm}^{3} \mathrm{~g}^{-1}\right)$ was much lower than these samples: $0.94 \mathrm{~cm}^{3} \mathrm{~g}^{-1}$ of K-Fe0.8-O, 0.91 $\mathrm{cm}^{3} \mathrm{~g}^{-1}$ of K-Fe0.8-M, and $0.78 \mathrm{~cm}^{3} \mathrm{~g}^{-1}$ of D-Fe0.8-M. This constituted one of the most important reasons that K-WG-O possessed much lower acetylene conversion activity than those of $\mathrm{K}-\mathrm{Fe} 0.8-\mathrm{O}$, $\mathrm{K}-\mathrm{Fe} 0.8-\mathrm{M}$, and D-Fe0.8-M, which will be detailedly discussed later in Section 2.3.

Table 1. Structure parameters of the prepared catalyst samples based on $\mathrm{N}_{2}$ adsorption/desorption.

\begin{tabular}{|c|c|c|c|c|c|c|}
\hline Samples & ${ }^{a} S_{B E T} / m^{2} g^{-1}$ & $\mathrm{~b} \mathrm{~V}_{\text {total }} / \mathrm{cm}^{3} \mathrm{~g}^{-1}$ & ${ }^{\mathrm{c}} \mathrm{V}_{\text {micro }} / \mathrm{cm}^{3} \mathrm{~g}^{-1}$ & ${ }^{d} V_{\text {meso }} / \mathrm{cm}^{3} \mathrm{~g}^{-1}$ & $\mathrm{~V}_{\text {meso }}\left(\mathrm{V}_{\text {total }}\right)^{-1 / \%}$ & ${ }^{\mathrm{e}} \mathrm{D} / \mathrm{nm}$ \\
\hline K-WG-O & 2137 & 1.31 & 0.97 & 0.35 & 26.3 & 0.96 \\
\hline K-S40-O & 1943 & 1.18 & 0.44 & 0.74 & 62.8 & 4.34 \\
\hline $\mathrm{K}-\mathrm{Fe} 0.8-\mathrm{O}$ & 2019 & 1.34 & 0.40 & 0.94 & 70.3 & 5.21 \\
\hline $\mathrm{K}-\mathrm{Fe} 0.8-\mathrm{M}$ & 1802 & 1.17 & 0.26 & 0.91 & 77.6 & 5.45 \\
\hline ZS-SD1-Fe0.8-M & 1498 & 0.82 & 0.116 & 0.704 & 85.8 & 7.11 \\
\hline
\end{tabular}

Further comparing the texture parameters of the samples of K-Fe0.8-O, K-Fe0.8-M and D-Fe0.8-M, it can be found that addition of $\mathrm{KCl}$ for the sample of $\mathrm{K}-\mathrm{Fe} 0.8-\mathrm{M}$ and D-Fe0.8-M could slightly decrease the related $\mathrm{S}_{\mathrm{BET}}\left(1802,1723 \mathrm{~m}^{2} \mathrm{~g}^{-1}\right)$ and $\mathrm{V}_{\text {total }}\left(1.17,1.03 \mathrm{~cm}^{3} \mathrm{~g}^{-1}\right)$ values, in comparison to those of $\mathrm{K}-\mathrm{Fe} 0.8-\mathrm{O}\left(\mathrm{S}_{\mathrm{BET}}=2019 \mathrm{~m}^{2} \mathrm{~g}^{-1}\right.$ and $\left.\mathrm{V}_{\text {total }}=1.34 \mathrm{~cm}^{3} \mathrm{~g}^{-1}\right)$. This is mainly due to that the $\mathrm{KCl}$ with relatively small dynamic diameter of $0.93 \mathrm{~nm}$ could readily diffuse into the micro- and mesopores of the AC substrate, resulting in the final decreases of pore volume as well as specific surface area. Meanwhile, it is also worth noticing that the sample of D-Fe0.8-M exhibited slightly lower $\mathrm{S}_{\mathrm{BET}}$ and $\mathrm{V}_{\text {total }}$ values than those of $\mathrm{K}-\mathrm{Fe} 0.8-\mathrm{M}$. This is due to the $\mathrm{KCl} / \mathrm{HgCl}_{2}$ step-by-step loading strategy applied during D-Fe0.8-M synthesis process: the $\mathrm{KCl}$ with lower dynamic diameter than that of $\mathrm{HgCl}_{2}$ could be much better dispersed inside the micro- and mesopores of the $\mathrm{Fe} 0.8$ - $\mathrm{AC}$ substrate, with respect to that of $\mathrm{K}-\mathrm{Fe} 0.8-\mathrm{M}$ prepared by $\mathrm{KCl} / \mathrm{HgCl}_{2}$ co-loading strategy.

\subsubsection{XRD}

Figure 3 displays the XRD patterns of the prepared samples. The broad peak centered at around $25^{\circ}$ can be assigned to the (002) reflection of the AC substrate [31,32], which verified the existence of micro-graphitic structure of the AC. Another sharp peak centered at $28.4^{\circ}$ can also be clearly observed for all samples, which can be assigned to the characteristic XRD pattern of the loaded $\mathrm{HgCl}_{2}$ species [33]. The FWHM (full width at half maximum) comparison result of the peak at $2 \theta$ $=28.4^{\circ}$ reveals that the loaded $\mathrm{HgCl}_{2}$ species could be much better dispersed over D-Fe0.8-O with respect to other samples and the $\mathrm{HgCl}_{2}$ dispersity decreased following the order of $\mathrm{D}-\mathrm{Fe} 0.8-\mathrm{M}>$ $\mathrm{K}-\mathrm{Fe} 0.8-\mathrm{M}>\mathrm{K}-\mathrm{Fe} 0.8-\mathrm{O}>\mathrm{K}-\mathrm{S} 40-\mathrm{O}>\mathrm{K}-\mathrm{S} 20-\mathrm{O}>\mathrm{K}-\mathrm{WG}-\mathrm{O}>\mathrm{K}-\mathrm{TX}-\mathrm{O}$. This result can be explained in two scenarios. Firstly, as for the samples of K-Fe0.8-O, K-S40-O, K-S20-O, K-WG-O and K-TX-O prepared by different types of $\mathrm{AC}$ substrate, the related $\mathrm{HgCl}_{2}$ dispersities were actually determined by the mesoporous volumes of the AC substrate, as listed in Table S2. Higher mesopore volume would much better facilitate dispersion of the loaded $\mathrm{HgCl}_{2}$. In the other scenario, wherein the samples of K-Fe0.8-O, K-Fe0.8-M and D-Fe0.8-M were prepared by the same AC substrate of Fe0.8-AC, D-Fe0.8-M 
and $\mathrm{K}-\mathrm{Fe} 0.8-\mathrm{M}$ possessed slightly lower mesopore volumes than that of $\mathrm{K}-\mathrm{Fe} 0.8-\mathrm{O}$, which however exhibited much better $\mathrm{HgCl}_{2}$ dispersities than that of $\mathrm{K}-\mathrm{Fe} 0.8-\mathrm{O}$. This is related to that the $\mathrm{KCl}$ with the dynamic diameter being lower than that of $\mathrm{HgCl}_{2}$ could largely occupy the micropores of the $\mathrm{Fe} 0.8$-AC substrate, resulting in the loaded $\mathrm{HgCl}_{2}$ species being mainly dispersed inside the mesopores, especially for $\mathrm{D}-\mathrm{Fe} 0.8-\mathrm{M}$ prepared by the $\mathrm{KCl} / \mathrm{HgCl}_{2}$ step-by-step loading approach, wherein the loaded $\mathrm{HgCl}_{2}$ species could be much better dispersed. As verified in Table 1, the micropore volumes of D-Fe0.8-M $\left(\mathrm{V}_{\text {micro }}=0.25 \mathrm{~cm}^{3} \mathrm{~g}^{-1}\right)$ and K-Fe $0.8-\mathrm{M}\left(\mathrm{V}_{\text {micro }}=0.26 \mathrm{~cm}^{3} \mathrm{~g}^{-1}\right)$ were greatly reduced after $\mathrm{KCl}$ addition, with respect to that of $\mathrm{K}-\mathrm{Fe} 0.8-\mathrm{O}\left(0.4 \mathrm{~cm}^{3} \mathrm{~g}^{-1}\right)$.

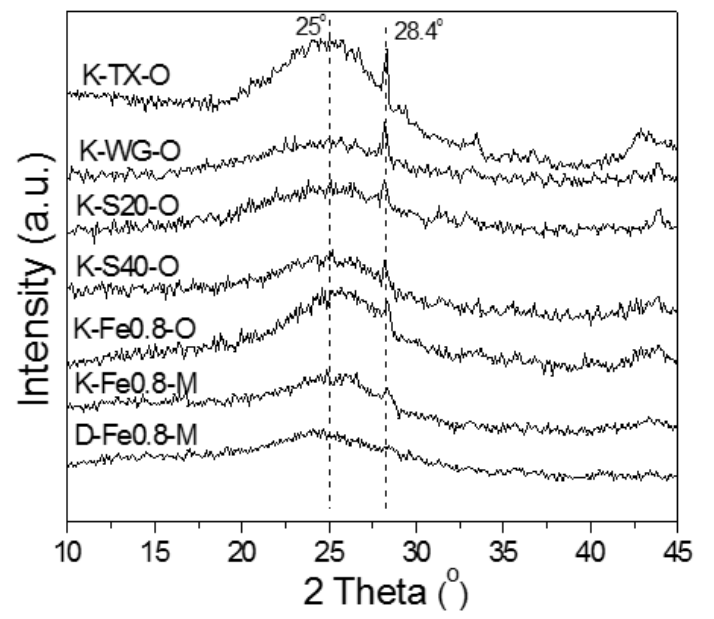

Figure 3. XRD patterns of the prepared catalysts samples: K-TX-O, K-WG-O, K-S20-O, K-S40-O, $\mathrm{K}-\mathrm{Fe} 0.8-\mathrm{O} ; \mathrm{K}-\mathrm{Fe} 0.8-\mathrm{M}$ and D-Fe0.8-M.

\subsubsection{SEM and Back Scattered Electron (BSE)}

In order to give direct evidence on $\mathrm{HgCl}_{2}$ surface dispersions, the surface morphologies as well as $\mathrm{HgCl}_{2}$ surface dispersion images of the samples of D-Fe0.8-M, K-Fe0.8-M, K-Fe0.8-O, K-S40-O, K-S20-O, K-WG-O and K-TX-O were further investigated by SEM and BSE, as shown in Figure 4A-G (SEM) and Figure $4 \mathrm{H}-\mathrm{N}$ (BSE), respectively. It can be found that the surface morphologies of $\mathrm{D}-\mathrm{Fe} 0.8-\mathrm{M}, \mathrm{K}-\mathrm{Fe} 0.8-\mathrm{M}$ and $\mathrm{K}-\mathrm{Fe} 0.8-\mathrm{O}$ were much smoother than those of other samples (see Figure 4A-G). Meanwhile, the BSE images reveal that the amounts of light spots, representing the loaded $\mathrm{HgCl}_{2}$ species, gradually increased from Figure $4 \mathrm{H}-\mathrm{N}$. These findings directly verified that the loaded $\mathrm{HgCl}_{2}$ species were well dispersed over D-Fe0.8-M, K-Fe0.8-M and K-Fe0.8-O, displaying small amounts of light spots (see Figure 4H-J). However, it became totally converse for the scenarios of K-WG-O (Figure 4M) and K-TX-O (Figure $4 \mathrm{~N}$ of BSE), displaying large amounts of light spots which were related to aggregation of the loaded $\mathrm{HgCl}_{2}$ species. The diverse results can be mainly related to the larger mesopore volumes of D-Fe0.8-M, K-Fe0.8-M and K-Fe0.8-O, which favored better dispersion of the $\mathrm{HgCl}_{2}$ species inside its mesopores; however, the larger micropore volume of $\mathrm{K}-\mathrm{WG}-\mathrm{O}\left(\mathrm{V}_{\text {micro }}=0.97 \mathrm{~cm}^{3} \mathrm{~g}^{-1}\right)$ and K-TX-O $\left(\mathrm{V}_{\text {micro }}=0.58 \mathrm{~cm}^{3} \mathrm{~g}^{-1}\right)$ resulted in $\mathrm{HgCl}_{2}$ species being readily aggregated on the surface of the $\mathrm{AC}$ substrate. Additionally, the amounts of light spots on the samples of D-Fe0.8-M (Figure 4H), K-Fe0.8-M (Figure 4I) and K-Fe0.8-O (Figure 4J), decreased following the order of D-Fe0.8-M > K-Fe0.8-M > $\mathrm{K}-\mathrm{Fe} 0.8-\mathrm{O}$, which further verified the results derived from $\mathrm{XRD}$ that addition of $\mathrm{KCl}$ on samples of $\mathrm{D}-\mathrm{Fe} 0.8-\mathrm{M}$ and $\mathrm{K}-\mathrm{Fe} 0.8-\mathrm{M}$ could improve the $\mathrm{HgCl}_{2}$ dispersions and much better $\mathrm{HgCl}_{2}$ dispersions could be obtained through $\mathrm{KCl} / \mathrm{HgCl}_{2}$ step-by-step loading approach. 

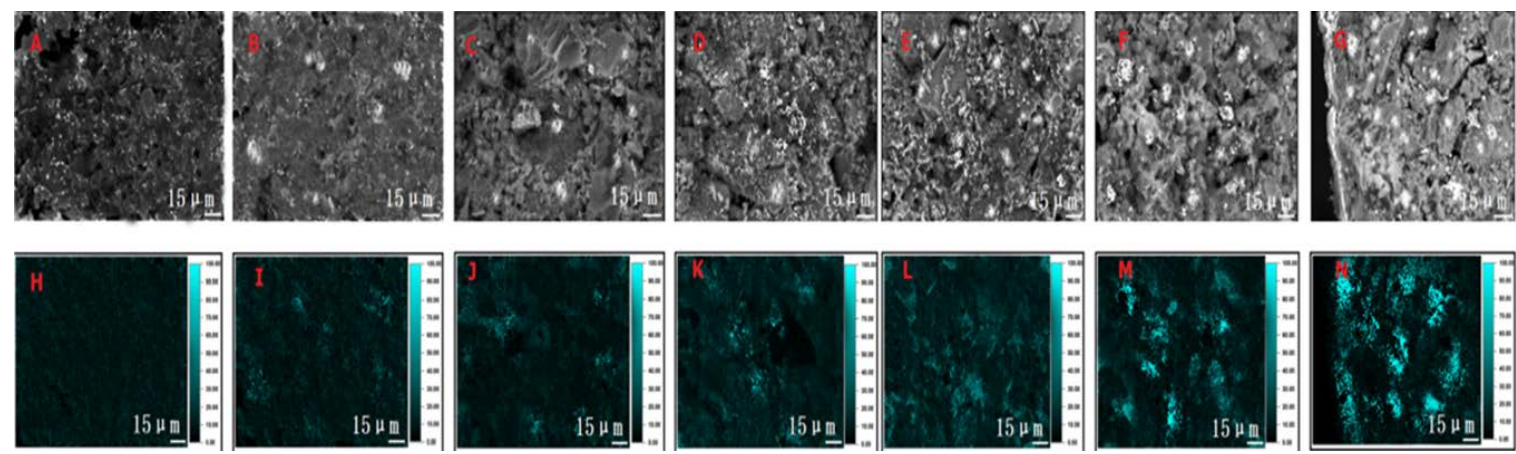

Figure 4. SEM images of the catalyst samples: (A) D-Fe0.8-M; (B) K-Fe0.8-M; (C) K-Fe0.8-O; (D) K-S40-O; (E) K-S20-O; (F) K-WG-O; (G) K-TX-O; BSE images of catalysts: (H) D-Fe0.8-M; (I) K-Fe0.8-M; (J) K-Fe0.8-O; (K) K-S40-O; (L) K-S20-O; (M) K-WG-O; (N) K-TX-O.

\subsubsection{TG}

TG was employed in this section to evaluate stability of the loaded $\mathrm{HgCl}_{2}$ species on the prepared samples, as shown in Figure 5. The peaks centered at $\sim 50{ }^{\circ} \mathrm{C}$ can be related to the weight loss of the adsorbed $\mathrm{H}_{2} \mathrm{O}$ on the AC substrate [14]. The peaks centered at around $250-400{ }^{\circ} \mathrm{C}$ were attributed to sublimations of the loaded $\mathrm{HgCl}_{2}$ species [34], and the corresponding sublimation temperatures decreased following the trend of D-Fe0.8-M > K-Fe0.8-M > K-Fe0.8-O > K-S40-O > K-S20-O > K-WG-O $>\mathrm{K}-\mathrm{TX}-\mathrm{O}$. This finding suggests that the $\mathrm{HgCl}_{2}$ species could be much more stably adsorbed on D-Fe0.8-M, K-Fe0.8-M and K-Fe0.8-O, with respect to other samples. This can be mainly due to that the $\mathrm{HgCl}_{2}$ species were largely dispersed inside the mesopores of $\mathrm{D}-\mathrm{Fe} 0.8-\mathrm{M}, \mathrm{K}-\mathrm{Fe} 0.8-\mathrm{M}$ and $\mathrm{K}-\mathrm{Fe} 0.8-\mathrm{O}$, which could exert strong adsorption effect on the loaded $\mathrm{HgCl}_{2}$ species. On the contrary, the $\mathrm{HgCl}_{2}$ species were mainly aggregated on the surface of K-WG-O and K-TX-O, which exerted relatively lower adsorption effect finally resulting in the loaded $\mathrm{HgCl}_{2}$ species being readily sublimated at lower temperatures. As for the samples of D-Fe0.8-M and K-Fe0.8-M, the $\mathrm{HgCl}_{2}$ sublimation temperatures on D-Fe0.8-M and K-Fe0.8-M was higher than that of K-Fe0.8-O, which reveals that the addition of $\mathrm{KCl}$ could further stabilize the loaded $\mathrm{HgCl}_{2}$ species. Meanwhile, higher $\mathrm{HgCl}_{2}$ sublimation temperature of $\mathrm{D}-\mathrm{Fe} 0.8-\mathrm{M}$ with respect to that of $\mathrm{K}-\mathrm{Fe} 0.8$-M suggested that the $\mathrm{KCl} / \mathrm{HgCl}_{2}$ step-by-step synthesis approach could further improve the $\mathrm{HgCl}_{2}$ loading stability.

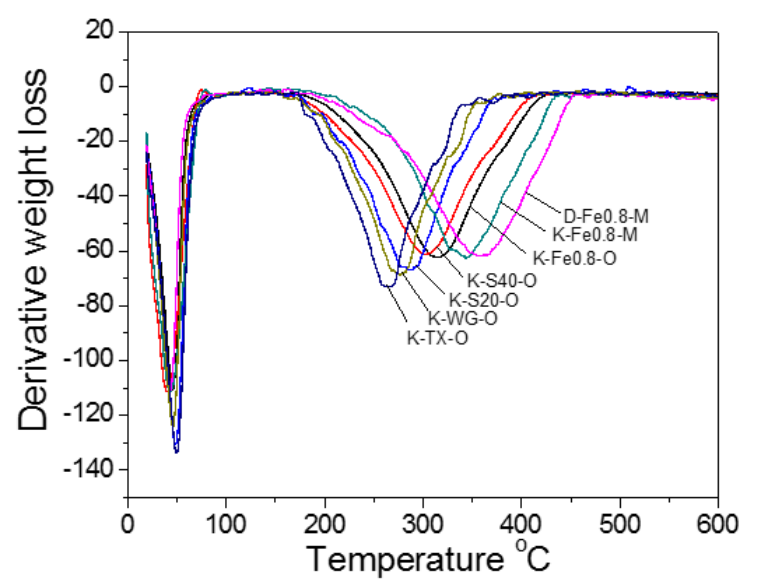

Figure 5. TG patterns of the catalyst samples (K-TX-O; K-WG-O; K-S20-O; K-S40-O; K-Fe0.8-O; K-Fe0.8-M).

In addition to that, some other factors could also influence the stability of the loaded $\mathrm{HgCl}_{2}$ species, including $\mathrm{Fe}_{3} \mathrm{O}_{4}$ additive and the carbon powder precursors (TX or HM). As stated in Supplementary Material of Characterization results of the $\mathrm{AC}$ substrates, the $\mathrm{Fe}_{3} \mathrm{O}_{4}$ addition can favor formation of 
mesopores, which thereby played a favorable role in enhancing surface dispersion as well as stability of the loaded $\mathrm{HgCl}_{2}$ species. As noted, due to greatly low loading amount of $\mathrm{Fe}_{3} \mathrm{O}_{4}(0.8 \mathrm{wt} \%)$, the effect of chemical interactions between $\mathrm{Fe}_{3} \mathrm{O}_{4}$ and $\mathrm{HgCl}_{2}$ could not be taken into account. As for the coal powders of TX and HM, the TX (93.78 wt \%) possesses higher C content than that of HM $(71.88 \mathrm{wt} \%)$, which preferred to generate micropores during AC substrate synthesis. However, the HM with lower $C$ content facilitated formation of mesopores. As verified by the texture parameters listed in Table $\mathrm{S} 2$, the TX-AC exhibited the highest $\mathrm{V}_{\text {micro }}\left(0.598 \mathrm{~cm}^{3} \mathrm{~g}^{-1}\right)$ value than those other samples [S20-AC $\left(0.435 \mathrm{~cm}^{3} \mathrm{~g}^{-1}\right)$, S40-AC $\left(0.453 \mathrm{~cm}^{3} \mathrm{~g}^{-1}\right)$ and $\left.\mathrm{Fe} 0.8-\mathrm{AC}\left(0.421 \mathrm{~cm}^{3} \mathrm{~g}^{-1}\right)\right]$ prepared by utilizing TX and $\mathrm{HM}$ mixture. In this aspect, the single TX precursor producing large amounts of micropores is negative for $\mathrm{HgCl}_{2}$ dispersion, which resulted in lower $\mathrm{HgCl}_{2}$ stability. The mixture precursor of TX and $\mathrm{HM}$ could generate mesopores, being favorable for $\mathrm{HgCl}_{2}$ dispersion and with high stability.

\subsection{Activity Measurement}

\subsubsection{Activity Test}

The activity measurement of acetylene catalytic abatement to produce highly purified $\mathrm{HCl}$ over the prepared samples was conducted in this section and with the results being profiled in Figure 6 . The reaction was conducted at $\mathrm{T}=120^{\circ} \mathrm{C}$ under the total pressure of $0.3 \mathrm{Mpa}$, GHSV of $4 \mathrm{~mL} \mathrm{~min}{ }^{-1} \mathrm{~g}^{-1}$ and reaction time of $20 \mathrm{~h}$. It can be found that the outlet $\mathrm{C}_{2} \mathrm{H}_{2}$ content decreased following the order of K-TX-O > K-WG-O > K-S20-O > K-S40-O > K-Fe0.8-O > K-Fe0.8-M > D-Fe0.8-M. Obviously, $\mathrm{D}-\mathrm{Fe} 0.8-\mathrm{M}$ possessing the lowest value of $\sim 0.25 \mathrm{ppm}$ exhibited the highest acetylene abatement activity. However, K-TX-O possessing the highest outlet $\mathrm{C}_{2} \mathrm{H}_{2}$ content of $\sim 1.4 \mathrm{ppm}$ exhibited the lowest acetylene conversion activity. The diverse activities of these samples can be mainly related to different surface dispersion abilities of the loaded $\mathrm{HgCl}_{2}$ species, which was greatly influenced by the utilized AC substrates as well as the $\mathrm{KCl}$ additive. The higher mesopore volume as well as the $\mathrm{KCl} / \mathrm{HgCl}_{2}$ step-by-step loading strategy resulted in the loaded $\mathrm{HgCl}_{2}$ species being well dispersed on D-Fe0.8-M; however, the AC substrate of K-TX-O with lower mesoporous volume resulted in ready aggregation of $\mathrm{HgCl}_{2}$ exhibiting greatly low $\mathrm{C}_{2} \mathrm{H}_{2}$ conversion activity. In light of the activity measurement results, it gives us a clue that the $\mathrm{AC}$ substrate possessing higher mesoporous structure would be much more favorable for $\mathrm{HgCl}_{2}$ dispersion, thereby resulting in much higher acetylene conversion activity. Additionally, the addition of $\mathrm{KCl}$, especially through $\mathrm{KCl} / \mathrm{HgCl}_{2}$ step-by-step approach, could further improve the catalytic activity to a certain degree due to promotion of the effect of $\mathrm{KCl}$ on $\mathrm{HgCl}_{2}$ dispersions.

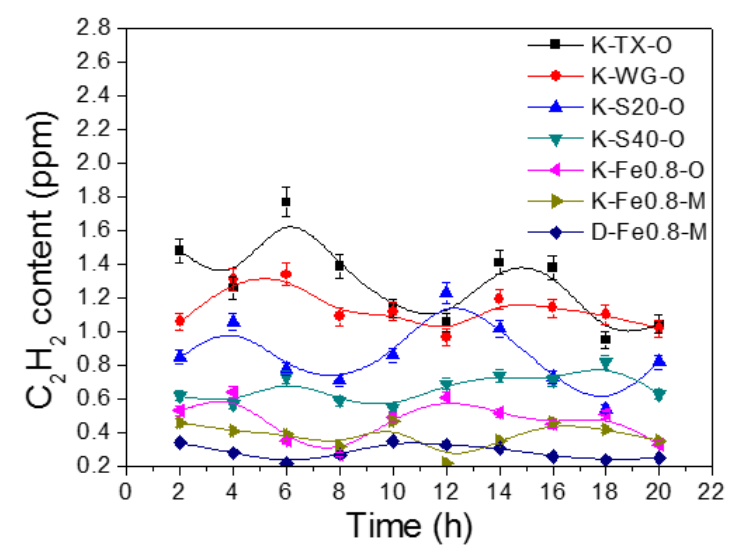

Figure 6. Catalytic abatement of acetylene through hydrochlorination over prepared samples (K-TX-O, K-WG-O, K-S20-O, K-S40-O, K-Fe0.8-O, K-Fe0.8-M, D-Fe0.8-M) at T = $120{ }^{\circ} \mathrm{C}$, total pressure of $0.3 \mathrm{Mpa}$, $\mathrm{GHSV}=4 \mathrm{~mL} \mathrm{~min}^{-1} \mathrm{~g}^{-1}, t=20 \mathrm{~h}$, and $2000 \mathrm{ppm} \mathrm{C}_{2} \mathrm{H}_{2}$ balanced by $\mathrm{HCl}(>99.5 \%)$, error bar of $5 \%$. 


\subsubsection{Long-Term Reaction Stability Test}

In order to further evaluate the thermal stabilities of the prepared samples, the acetylene catalytic abatement was conducted at higher temperature of $160^{\circ} \mathrm{C}$ and higher GHSV of $10 \mathrm{~mL} \mathrm{~min}^{-1} \mathrm{~g}^{-1}: 100 \mathrm{~h}$ over K-TX-O, K-WG-O, K-S20-O and K-S40-O of Figure 7a; and $240 \mathrm{~h}$ over K-Fe0.8-O, K-Fe0.8-M and $\mathrm{D}-\mathrm{Fe} 0.8-\mathrm{M}$ of Figure $7 \mathrm{~b}$. As shown in Figure 7a, the outlet acetylene content gradually increased after $60 \mathrm{~h}$ 's stable reaction: from 3.0 to $4.5 \mathrm{ppm}$ for K-TX-O; from 2.8 to $4.0 \mathrm{ppm}$ for K-WG-O; from 2.5 to $3.8 \mathrm{ppm}$ for K-S20-O; and from 1.5 to $2.5 \mathrm{ppm}$ for K-S40-O. Much better thermal stabilities could be found for the samples of $\mathrm{D}-\mathrm{Fe} 0.8-\mathrm{M}, \mathrm{K}-\mathrm{Fe} 0.8-\mathrm{M}$ and $\mathrm{K}-\mathrm{Fe} 0.8-\mathrm{O}$, exhibiting the stable acetylene conversion activities at the time range of $(0-160 \mathrm{~h})$ for K-Fe0.8-O, $(0-180 \mathrm{~h})$ for K-Fe0.8-M and $(0-220 \mathrm{~h})$ for D-Fe0.8-M. In light of above results, it can be found that the sample of D-Fe0.8-M exhibited the best long-term stability during $\mathrm{C}_{2} \mathrm{H}_{2}$ abatement during $\mathrm{HP}-\mathrm{HCl}$ production. There are two main factors leading to deactivations of these catalyst samples: (i) loss of active species of $\mathrm{HgCl}_{2}$ after long-time reaction; (ii) accumulation of the generated product of vinyl chloride $\left(\mathrm{C}_{2} \mathrm{H}_{3} \mathrm{Cl}\right)$ inside the catalysts. The detailed investigations will be further conducted in the following Section 2.2.3 based on the sample of D-Fe0.8-M.
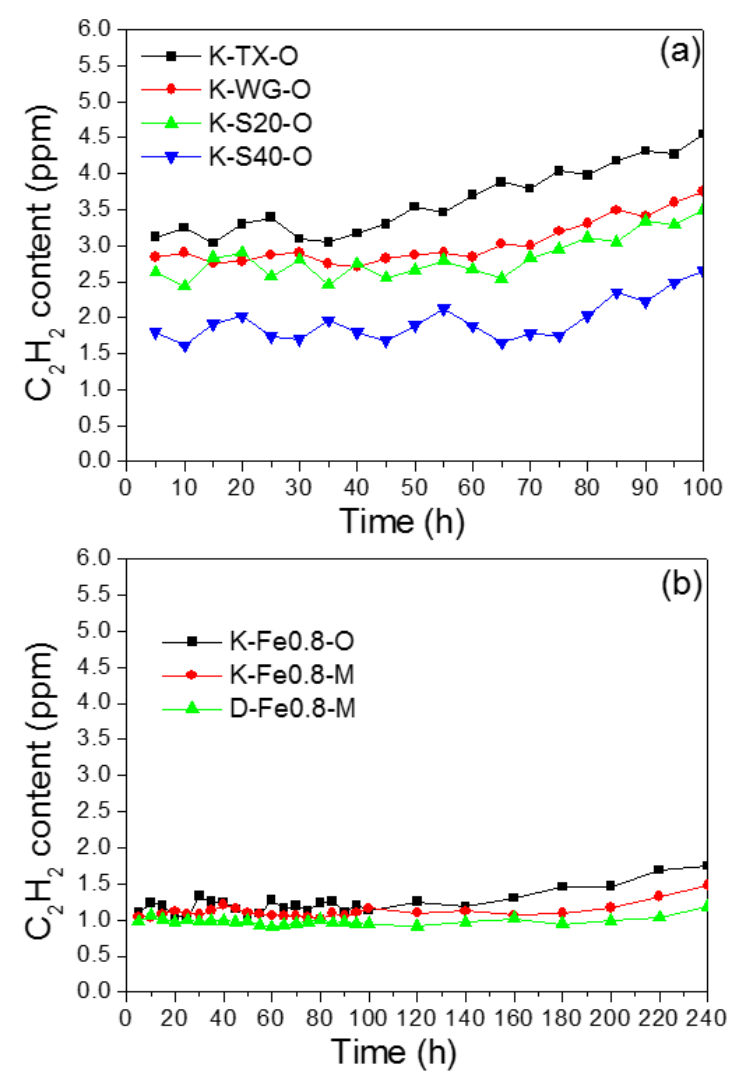

Figure 7. Long-term stability test during catalytic abatement of acetylene through hydrochlorination over prepared samples (a) K-TX-O, K-WG-O, K-S20-O, K-S40-O ( $t=100 \mathrm{~h}$ ); and (b) K-Fe0.8-O, $\mathrm{K}-\mathrm{Fe} 0.8-\mathrm{M}, \mathrm{D}-\mathrm{Fe} 0.8 \mathrm{-M}(t=240 \mathrm{~h})$; at $\mathrm{T}=160{ }^{\circ} \mathrm{C}$, total pressure of $0.3 \mathrm{Mpa}, \mathrm{GHSV}=10 \mathrm{~mL} \mathrm{~min}{ }^{-1} \mathrm{~g}^{-1}$, $t=100 \mathrm{~h}$; and 2000 ppm $\mathrm{C}_{2} \mathrm{H}_{2}$ balanced by $\mathrm{HCl}$ (>99.5\%); error bar of $5 \%$.

\subsubsection{Deactivation and Reactivation of the D-Fe0.8-M}

In this part, the deactivation and reactivation of D-Fe0.8-M was further investigated based on EDS (Figure 8a-d), FI-IR (Figure 9a) and in-situ Diffuse reflectance infrared Fourier transform spectra (DRIFTS) (Figure 9b). The deactivated D-Fe0.8-M was defined as the sample resulting in $\mathrm{C}_{2} \mathrm{H}_{2}$ outlet content being higher than $1.0 \mathrm{ppm}$, which was relabeled as SD1-Fe0.8-M. The related texture parameters were also listed in Table 1. It can be found that the pore volume, including micro- and mesopore 
volumes and specific surface area of SD1-Fe0.8-M were greatly decreased, with respect to that of D-Fe0.8-M.
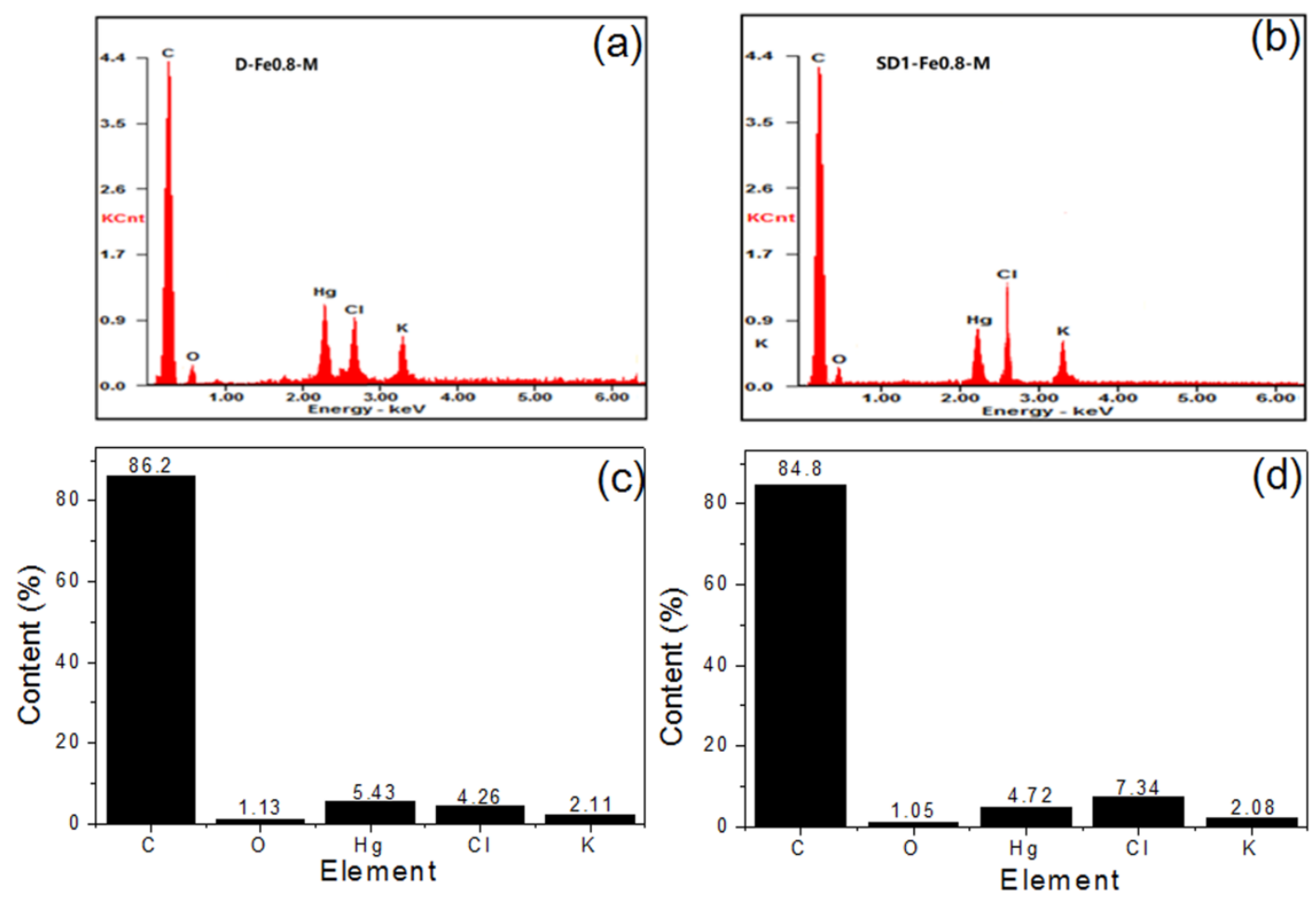

Figure 8. EDS of (a) active D-Fe0.8-M and (b) deactivated SD1-Fe0.8-M; element content derived from EDS of (c) active D-Fe0.8-M; and (d) deactivated SD1-Fe0.8-M

Figure 8a-d compared the EDS results of active and deactivated D-Fe0.8-M, it can be found that the element content of $\mathrm{Hg}$ on SD1-Fe0.8-M slightly decreased from $5.43 \%$ to $4.72 \%$; however, the $\mathrm{Cl}$ content (representing the product of $\mathrm{C}_{2} \mathrm{H}_{3} \mathrm{Cl}$ ) greatly increased from $4.28 \%$ to $7.34 \%$. This finding verified that the deactivation of $\mathrm{D}-\mathrm{Fe} 0.8-\mathrm{M}$ could be related to loss of $\mathrm{HgCl}_{2}$ active species and accumulations of the $\mathrm{C}_{2} \mathrm{H}_{3} \mathrm{Cl}$, especially for the later one. In addition to that, the deactivated sample of SD1-Fe0.8-M was further characterized by FT-IR, as shown in Figure 9a. The small vibration peaks centered at 3316 and $3255 \mathrm{~cm}^{-1}$ can be related to $v[\mathrm{C}-\mathrm{H}]$ of $\mathrm{C}_{2} \mathrm{H}_{2}$ and the peak of $2869 \mathrm{~cm}^{-1}$ was related to $v[\mathrm{H}-\mathrm{Cl}]$ of the adsorbed $\mathrm{HCl}$ [35]. While the extensive peaks of 3093, 1604, 1018 and $933 \mathrm{~cm}^{-1}$ were respectively related to $v[\mathrm{C}-\mathrm{H}]\left(3093 \mathrm{~cm}^{-1}\right), v[\mathrm{C}=\mathrm{C}]\left(1604,1018 \mathrm{~cm}^{-1}\right)$ and $v\left[\mathrm{CH}_{2}\right]\left(933 \mathrm{~cm}^{-1}\right)$ of $\mathrm{C}_{2} \mathrm{H}_{3} \mathrm{Cl}$ [36]. This finding further verified accumulation of $\mathrm{C}_{2} \mathrm{H}_{3} \mathrm{Cl}$ product on the deactivated sample of SD1-Fe0.8-M.

The in-situ DRIFTS was thereafter conducted during SD1-Fe0.8-M reactivation, wherein the deactivated sample was treated by $\mathrm{HCl}\left(10 \mathrm{~mL} \mathrm{~min}^{-1}\right)$ at $\mathrm{T}=220^{\circ} \mathrm{C}$ for $60 \mathrm{~h}$, as shown in Figure $9 \mathrm{~b}$. After $20 \mathrm{~h}$ 's $\mathrm{HCl}$ treatment the adsorbed $\mathrm{C}_{2} \mathrm{H}_{2},\left(v[\mathrm{C} \equiv \mathrm{H}]=3316\right.$ and $\left.3255 \mathrm{~cm}^{-1}\right)$ totally vanished. Meanwhile, along with increasing of the $\mathrm{HCl}$ treatment time, the characteristic IR vibration peaks $\left(3093,1604,1018\right.$ and $\left.933 \mathrm{~cm}^{-1}\right)$ of the adsorbed $\mathrm{C}_{2} \mathrm{H}_{3} \mathrm{Cl}$ also extensively decreased. After that, the reactivated sample that was treated by $\mathrm{HCl}$ for $60 \mathrm{~h}$ and named as ZS-SD1-Fe0.8-M was further characterized by $\mathrm{N}_{2}$ adsorption/desorption and EDS. The results were respectively listed in Table 1 (texture parameters) and Figure S4 (EDS). As listed in Table 1, it can be found that after $\mathrm{HCl}$ treatment the specific surface free area and pore volume, especially for the mesopore volume of ZS-SD1-Fe0.8-M $\left(\mathrm{S}_{\mathrm{BET}}=1498 \mathrm{~m}^{2} \mathrm{~g}^{-1}, \mathrm{~V}_{\text {meso }}=0.704 \mathrm{~cm}^{3} \mathrm{~g}^{-1}\right)$ were increased to a certain degree, with respect to those of SD1-Fe0.8-M $\left(\mathrm{S}_{\text {BET }}=1215 \mathrm{~m}^{2} \mathrm{~g}^{-1}, \mathrm{~V}_{\text {meso }}=0.60 \mathrm{~cm}^{3} \mathrm{~g}^{-1}\right)$. The EDS results of ZS-SD1-Fe0.8-M shown in Figure $\mathrm{S} 4$ also suggests decline of the $\mathrm{Cl}$ content from 7.34\% (SD1-Fe0.8-M) to 4.71\%, which was comparable to the value of $4.26 \%$ of the active D-Fe0.8-M. 


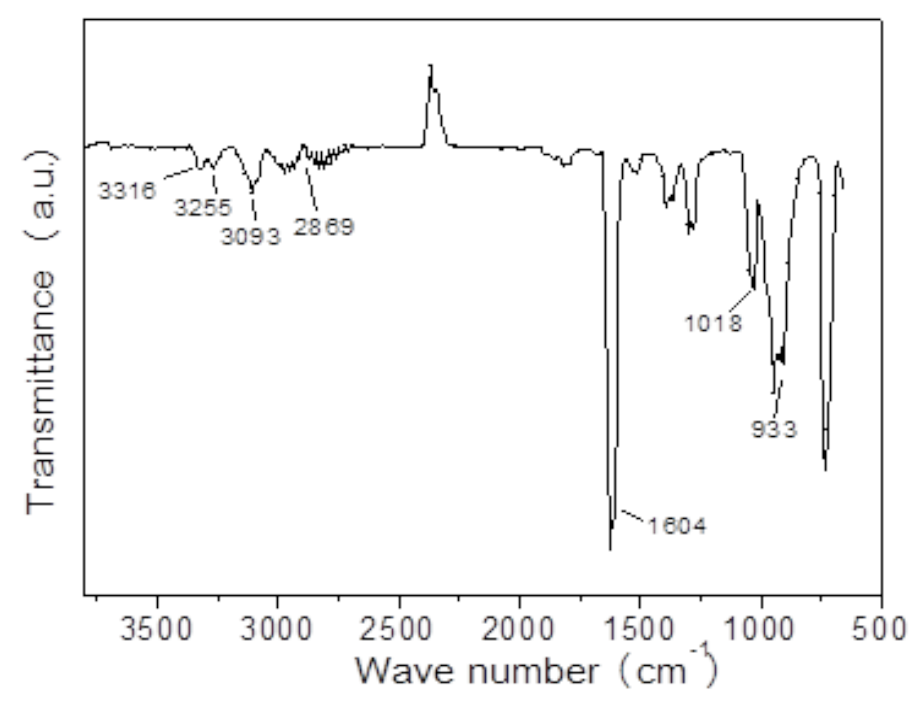

(a)

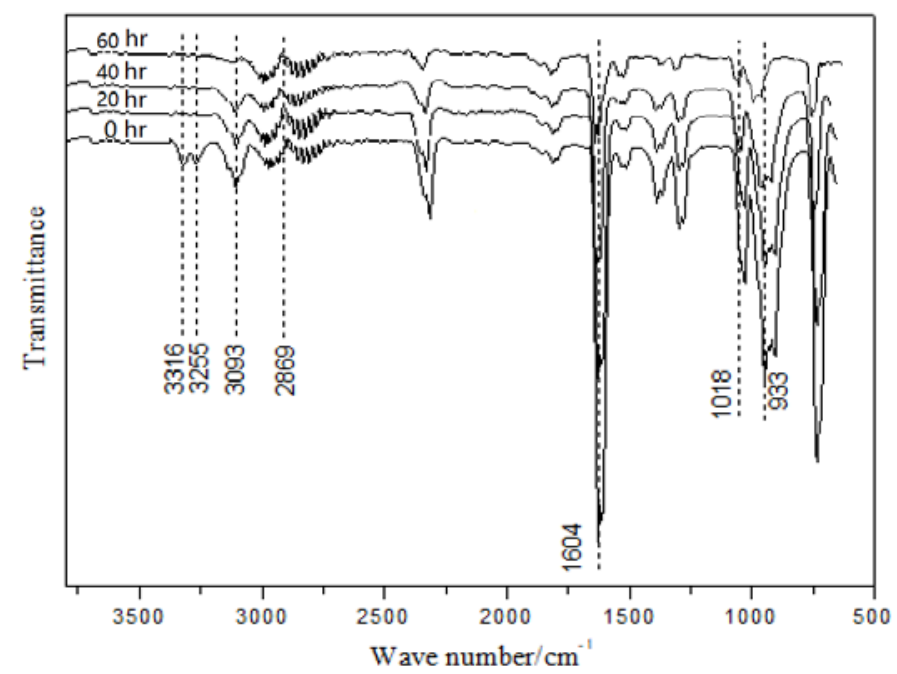

(b)

Figure 9. (a) FT-IR spectra of deactivated sample of SD1-Fe0.8-M; (b) in-situ Diffuse reflectance infrared Fourier transform spectra (DRIFTS) spectra during reactivation of SD1-Fe0.8-M treated by $10 \mathrm{~mL} \mathrm{~min}^{-1}$ $\mathrm{HCl}$ at $\mathrm{T}=220^{\circ} \mathrm{C}$ and over $60 \mathrm{~h}$.

The activity measurement, as well as long-term stability test over the reactivated sample of ZS-SD1-Fe0.8-M, was further conducted and with the results being compared to those of the active sample of D-Fe0.8-M, as shown in Figure 10a,b. It was revealed that the activity of ZS-SD1-Fe0.8-M was comparable to that of D-Fe0.8-M (see Figure 10a) at the investigated time of $20 \mathrm{~h}$; and slight decrease of the lifetime was observed for ZS-SD1-Fe0.8-M $(t=190 \mathrm{~h})$ with respect to D-Fe0.8-M $(t=220 \mathrm{~h})$. Herein, the lifetime was defined as the time when $\mathrm{C}_{2} \mathrm{H}_{2}$ outlet content was lower than $1.0 \mathrm{ppm}$ over the investigated catalyst sample under the reaction condition of $\mathrm{T}=160^{\circ} \mathrm{C}$, total pressure of $0.3 \mathrm{Mpa}, \mathrm{GHSV}=10 \mathrm{~mL} \mathrm{~min}{ }^{-1} \mathrm{~g}^{-1}$. Therefore, it can be concluded that the $\mathrm{HgCl}_{2}$ losing and $\mathrm{C}_{2} \mathrm{H}_{3} \mathrm{Cl}$ accumulation constituted the main reasons resulting in deactivation of D-Fe0.8-M; and the $\mathrm{HCl}$ treatment $\left(\mathrm{at} \mathrm{T}=220^{\circ} \mathrm{C}\right.$ ) could efficiently make it reactive again, with slightly lower lifetime than the active sample. 

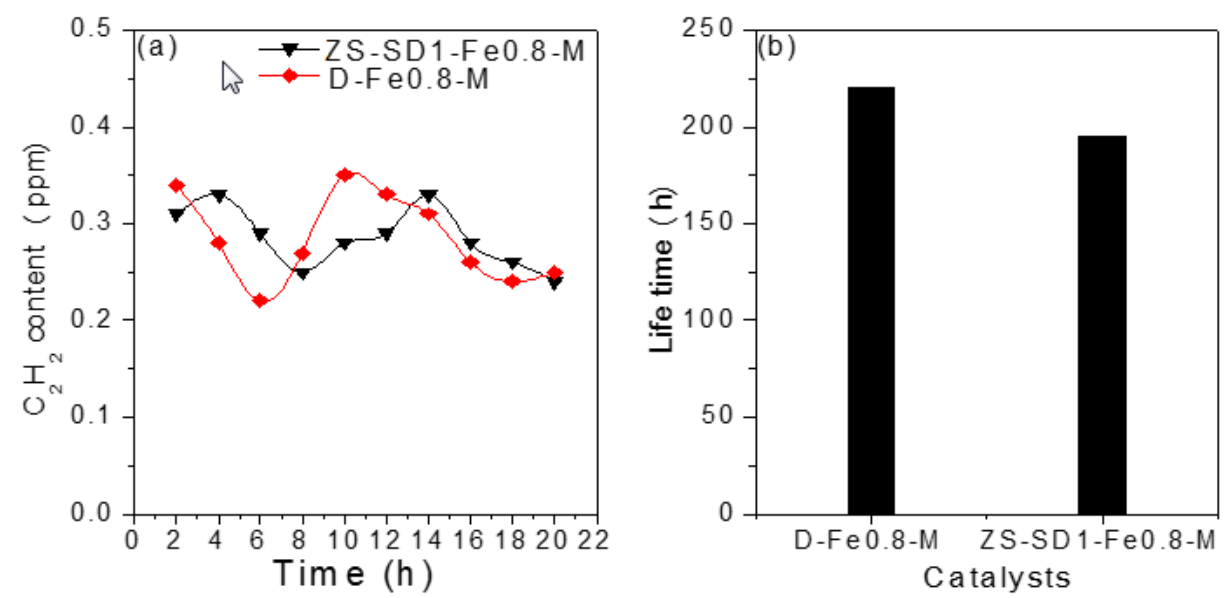

Figure 10. (a) activity measurement over ZS-SD1-Fe0.8-M and D-Fe0.8-M; reaction conditions: $\mathrm{T}=120{ }^{\circ} \mathrm{C}$, total pressure of $0.3 \mathrm{Mpa}$, GHSV $=4 \mathrm{~mL} \mathrm{~min}^{-1} \mathrm{~g}^{-1}, t=20 \mathrm{~h}$, and $2000 \mathrm{ppm} \mathrm{C}_{2} \mathrm{H}_{2}$ balanced by $\mathrm{HCl}(>99.5 \%$ ); error bar of 5\%; (b) lifetime comparison of ZS-SD1-Fe0.8-M and D-Fe0.8-M; the lifetime is defined as the time when the effluent $\mathrm{C}_{2} \mathrm{H}_{2}$ content being lower than $1 \mathrm{ppm}$ under reaction condition of $\mathrm{T}=160{ }^{\circ} \mathrm{C}$, total pressure of $0.3 \mathrm{Mpa}$, GHSV $=10 \mathrm{~mL} \mathrm{~min}^{-1} \mathrm{~g}^{-1}$ and $2000 \mathrm{ppm} \mathrm{C}_{2} \mathrm{H}_{2}$ balanced by $\mathrm{HCl}$ (>99.5\%).

\subsection{Correlation between Physicochemical Property and Activity Performance}

As stated above, the samples of D-Fe0.8-M, K-Fe0.8-M and K-Fe0.8-O exhibited much higher $\mathrm{C}_{2} \mathrm{H}_{2}$ conversion activity as well as reaction stability than those of K-TX-O, K-WG-O, K-S20-O and K-S40-O during acetylene catalytic abatement. This can be related to the much higher mesoporous volumes of D-Fe0.8-M, K-Fe0.8-M and K-Fe0.8-O with respect to other samples. On the one hand, the larger mesoporous volume greatly facilitated better dispersions of the loaded $\mathrm{HgCl}_{2}$ species. As revealed by XRD, SEM and BSE, the loaded $\mathrm{HgCl}_{2}$ species could be well-dispersed on D-Fe0.8-M, K-Fe0.8-M and $\mathrm{K}-\mathrm{Fe} 0.8-\mathrm{O}$, which were mainly dispersed inside the mesopores; however, large amounts of the aggregated $\mathrm{HgCl}_{2}$ species were clearly observed on the surface of K-TX-O, K-WG-O, K-S20-O and K-S40-O. Obviously, the well dispersed $\mathrm{HgCl}_{2}$ species working as the active center would exhibit much higher $\mathrm{C}_{2} \mathrm{H}_{2}$ conversion activity than those of the aggregated $\mathrm{HgCl}_{2}$ particles. For the samples of K-TX-O, K-WG-O, K-S20-O and K-S40-O, the related $\mathrm{C}_{2} \mathrm{H}_{2}$ conversion activity increased following the order of K-TX-O < K-WG-O < K-S20-O < K-S40-O, which was also consistent with the increasing order of the related mesoporous volume listed in Table 1: [K-TX-O $\left(0.23 \mathrm{~cm}^{3} \mathrm{~g}^{-1}\right)>\mathrm{K}-\mathrm{WG}-\mathrm{O}\left(0.35 \mathrm{~cm}^{3} \mathrm{~g}^{-1}\right)>$ $\left.\mathrm{K}-\mathrm{S} 20-\mathrm{O}\left(0.38 \mathrm{~cm}^{3} \mathrm{~g}^{-1}\right)>\mathrm{K}-\mathrm{S} 40-\mathrm{O}\left(0.74 \mathrm{~cm}^{3} \mathrm{~g}^{-1}\right)\right]$. On the other hand, the mesopores could exert strong adsorption effect on the loaded $\mathrm{HgCl}_{2}$ species; however, the micropore would exhibit low adsorption effect on the loaded $\mathrm{HgCl}_{2}$ species, especially for the aggregated $\mathrm{HgCl}_{2}$ particles. As revealed by $\mathrm{TG}$ of Figure 5, the $\mathrm{HgCl}_{2}$ species were much more stably adsorbed on the samples of D-Fe0.8-M, K-Fe0.8-M and $\mathrm{K}-\mathrm{Fe} 0.8-\mathrm{O}$ which also exhibited much higher reaction stabilities than other samples, as clearly observed in long-term test of Figure 7.

In addition to that, as revealed by XRD, BSE and TG and activity measurement results, the $\mathrm{KCl}$ additive was found to further enhance $\mathrm{HgCl}_{2}$ dispersities and adsorption stabilities on the sample of D-Fe0.8-M and K-Fe0.8-M, which resulted in higher $\mathrm{C}_{2} \mathrm{H}_{2}$ conversion activities and long-term stabilities than that of $\mathrm{K}-\mathrm{Fe} 0.8-\mathrm{O}$ synthesized without $\mathrm{KCl}$ addition. This can be mainly related to the strong interactions between $\mathrm{KCl}$ additives and the loaded $\mathrm{HgCl}_{2}$ species. Meanwhile, as for the samples of D-Fe0.8-M and K-Fe0.8-M, the first one displayed higher $\mathrm{C}_{2} \mathrm{H}_{2}$ conversion activity and better long-term stability than those of the later one. This is due to the $\mathrm{KCl} / \mathrm{HgCl}_{2}$ step-by-step loading strategy applied during D-Fe0.8-M synthesis process, wherein the initially loaded $\mathrm{KCl}$ could firstly occupy the micropores and resulted in the following loaded $\mathrm{HgCl}_{2}$ species being mainly dispersed 
inside the mesopores. This leads to much better $\mathrm{HgCl}_{2}$ dispersities than the scenario of $\mathrm{K}-\mathrm{Fe} 0.8-\mathrm{M}$ which was synthesized by $\mathrm{KCl} / \mathrm{HgCl}_{2}$ co-loading approach.

\section{Experimental}

\subsection{Catalyst Preparation}

\subsubsection{AC Substrate Preparation}

Five types of AC substrates were employed in present work named TX-AC, S20-AC, S40-AC, Fe0.8-AC and WG-AC. The first four types of substrates were prepared in laboratory based on two kinds of carbon powders being respectively abbreviated as TX and HM, while the last one (WG-AC) was a commercial product being utilized as a reference sample. As noted, the carbon power of TX and HM were two types of commercial products produced by Boteli Active Carbon Production Company in Ningxia of China. The elementary compositions of TX and HM were listed in Table S1 and the structural parameters of these prepared AC substrates were additionally listed in Table S2 of Supporting Information.

The preparation strategies for the substrate of TX-AC are detailedly described as follows: (i) the TX-AC was prepared by mixing TX carbon powder, $\mathrm{H}_{2} \mathrm{O}$, zetar (commercial product of Boteli Active Carbon Production Company, Shizuishan, China), and $\mathrm{KOH}$ together in the stainless steel pugmill according to the weight ratio of 89:8:1.5:1.5; (ii) after two hours milling, the mixture was dried at $40{ }^{\circ} \mathrm{C}$ for $5 \mathrm{~h}$, which was then carbonized at $450^{\circ} \mathrm{C}$ for $1 \mathrm{~h}$; (iii) finally, the TX-AC product was obtained after further activation at $\mathrm{T}=850^{\circ} \mathrm{C}$ for $30 \mathrm{~min}$.

The samples of S20-AC and S40-AC were prepared by a mixture of TX, $\mathrm{HM}, \mathrm{H}_{2} \mathrm{O}$, zetar, and $\mathrm{KOH}$ according to the mixing weight ratio of 44.25:44.25:8:1.5:2. Similar preparation procedure to that of TX-AC was applied during S20-AC and S40-AC preparations, except that the final activation time at $\mathrm{T}=850^{\circ} \mathrm{C}$ was respectively set to be 20 and $40 \mathrm{~min}$.

As for Fe0.8-AC, it was prepared by mixing TX, HM, $\mathrm{H}_{2} \mathrm{O}$, zetar, $\mathrm{KOH}$ and $\mathrm{Fe}_{3} \mathrm{O}_{4}$ together at the weight ratio of 43.85:43.85:8:1.5:2:0.8. The similar procedure to that of TX-AC was also applied, wherein the final product was obtained after activation at $\mathrm{T}=850{ }^{\circ} \mathrm{C}$ for $40 \mathrm{~min}$. As noted, there are two functions of the zetar played during AC preparation process: (i) working as the binder can well bind the coal powder together; (ii) working as pore-forming materials can create pores during the $\mathrm{AC}$ carbonization process.

\subsubsection{Low-mercury AC-Supported Catalysts Preparation}

The low-mercury-supported catalysts were prepared by the impregnation method based on the above-prepared substrates, wherein the $40 \mathrm{~g}$ AC substrate was mixed with $5.5 \mathrm{wt} \% \mathrm{HgCl}_{2}$ solution ( $2.33 \mathrm{~g} \mathrm{HgCl}_{2}$ was dissolved into $40 \mathrm{~mL}$ deionized water) stirring for $2 \mathrm{~h}$ and then dried at $90^{\circ} \mathrm{C}$ for $5 \mathrm{~h}$. The prepared samples were respectively labeled as K-TX-O, K-S20-O, K-S40-O, K-Fe0.8-O and K-WG-O, wherein the $\mathrm{K}$ represents the loading amount of $\mathrm{HgCl}_{2}(5.5 \mathrm{wt} \%)$ and $\mathrm{O}$ represents only $\mathrm{HgCl}_{2}$ being loaded on the AC substrate. As noted, in present work the loading amounts of $\mathrm{HgCl}_{2}$ species on each prepared AC substrate were same to each other with the value being of $\sim 5.5 \mathrm{wt} \%$.

In order to further evaluate the influence of $\mathrm{KCl}$ additive on acetylene catalytic abatement during $\mathrm{HP}-\mathrm{HCl}$ production process, two types of samples were prepared based on the impregnation method, which were respectively named as $\mathrm{K}-\mathrm{Fe} 0.8-\mathrm{M}$ and $\mathrm{D}-\mathrm{Fe} 0.8-\mathrm{M}$. As noted, the $\mathrm{M}$ of $\mathrm{K}-\mathrm{Fe} 0.8-\mathrm{M}$ and D-Fe0.8-M represent multiple contents $\left(\mathrm{HgCl}_{2}\right.$ and $\left.\mathrm{KCl}\right)$ being loaded on the $\mathrm{Fe} 0.8$ - $\mathrm{AC}$ substrate. The detailed synthesis procedures of K-Fe0.8-M were stated below: (i) $40 \mathrm{~g}$ substrate of $\mathrm{Fe} 0.8-\mathrm{AC}$ was mixed with $40 \mathrm{~mL}$ solution containing $5.5 \mathrm{wt} \% \mathrm{HgCl}_{2}$ and $2 \mathrm{wt} \% \mathrm{KCl}$ and stirring for $2 \mathrm{~h}$; (ii) then the final product was obtained after drying at $90{ }^{\circ} \mathrm{C}$ for $5 \mathrm{~h}$. Similar strategy was applied during $\mathrm{D}-\mathrm{Fe} 0.8-\mathrm{M}$ synthesis process, except that the $\mathrm{KCl}(2 \mathrm{wt} \%)$ and $\mathrm{HgCl}_{2}(5.5 \mathrm{wt} \%)$ were step by step loaded on $\mathrm{Fe} 0.8$ - $\mathrm{AC}$ substrate, wherein the $\mathrm{KCl}$ was firstly mixed with $\mathrm{Fe} 0.8$ - $\mathrm{AC}$ string for $2 \mathrm{~h}$ and the 
then $\mathrm{HgCl}_{2}$ was introduced into the synthesis system. The D of D-Fe0.8-M represents step by step loading of $\mathrm{KCl}$ and $\mathrm{HgCl}_{2}$ on $\mathrm{Fe} 0.8-\mathrm{M}$ substrate.

\subsection{Catalyst Characterization}

The specific surface area $\left(\mathrm{S}_{\mathrm{BET}}\right)$ and micropore volume $\left(\mathrm{V}_{\text {micro }}\right)$ were measured by nitrogen adsorption/desorption over Sorptomatic 1990 instrument (Thermo Electron, Waltham, MA, USA), wherein the $\mathrm{S}_{\mathrm{BET}}$ was obtained through Brunauer-Emmett-Teller (BET) method and the $\mathrm{V}_{\text {micro }}$ was determined by the approach of $t$-plot. The pore-size distributions were calculated by Barrett-JoynerHalenda (BJH) method.

$\mathrm{X}$-ray diffraction (XRD) was conducted on a X-ray diffractometer (Bruker D8 type, Bruker, Karlsruher, Germany) with $\mathrm{Cu} \mathrm{K} \alpha$ irradiation and nickel filter $(\lambda=1.5406 \AA)$ and $2 \theta$ ranging from 10 to $45^{\circ}$. The surface morphologies of the samples were investigated on a TESCAN MIRA3 scanning electron microscope (SEM, TESCAN, Brno, Czech Republic), based on which the back scattered electron (BSE) images of the loaded $\mathrm{HgCl}_{2}$ species were further analyzed to illustrate their surface dispersions.

For the purpose of evaluating the thermal stabilities of the loaded $\mathrm{HgCl}_{2}$ species on the prepared AC substrates, the thermogravimetry (TG) was conducted over NRTZSCH sta-449C (NETZSCH, Selb, Germany), wherein the sample of $0.04 \mathrm{~g}$ was heated from 0 to $1000{ }^{\circ} \mathrm{C}\left(10^{\circ} \mathrm{C} \mathrm{min}{ }^{-1}\right)$ under the $\mathrm{N}_{2}$ atmosphere $\left(100 \mathrm{~mL} \mathrm{~min}^{-1}\right)$. Energy-dispersive $\mathrm{X}$-ray spectroscopy (EDS) was also conducted over GeminiSEM 300 (Carl Zeiss AG, Jena, Germany) to study the element content of the prepared samples.

The Fourier transform infrared spectroscopy (FI-IR) and in situ Diffuse reflectance infrared Fourier transform spectra (in-situ DRIFTS) was conducted on Nicolet Is10 (Thermo Electron, Waltham, MA, USA), equipped with an MCT detector. The catalyst samples were diluted by $\mathrm{KBr}$ during both FI-IR and in-situ DRIFTS investigations. During the in-situ DRIFTS investigation, the $\mathrm{KBr}$ diluted catalyst sample $(\sim 1 \mathrm{mg})$ was placed into the diffuse reflectance cell and heated up to $\mathrm{T}=220^{\circ} \mathrm{C}$. The IR signal was recorded after $\mathrm{HCl}\left(10 \mathrm{~mL} \mathrm{~min}^{-1}\right)$ being introduced into the system at each $20 \mathrm{~h}\left(\mathrm{t}_{\text {total }}=60 \mathrm{~h}\right)$. The resolution of $4 \mathrm{~cm}^{-1}$ and accumulation of 100 scans were applied during DRIFTS test. As noted, the characterization results of the five types of AC substrates (TX-AC, S20-AC, S40-AC, Fe0.8-AC and WG-AC) were detailedly summarized in Supporting Information.

\subsection{Activity Test}

Activity measurements for acetylene catalytic abatement were carried out through a fixed-bed reactor $(\Phi 14 \times 2 \times \mathrm{L} 300 \mathrm{~mm})$ under total pressure of $0.3 \mathrm{Mpa}, \mathrm{T}$ of $120^{\circ} \mathrm{C}$, and reaction time of $20 \mathrm{~h}$. $10 \mathrm{~g}$ of pelletized catalyst with particle sizes of $0.85-2.0 \mathrm{~mm}$ was placed in the constant temperature zone $(\sim 150 \mathrm{~mm})$ of the vertical tubular reactor. The reactant gas mixtures, consisting of $2000 \mathrm{ppm}$ $\mathrm{C}_{2} \mathrm{H}_{2}$ balanced by $\mathrm{HCl}(>99.5 \%)$, were fed into the reactor in a total flow rate of $40 \mathrm{~mL} \mathrm{~min}^{-1}$ being corresponding to the GHSV (gas hourly space velocity) of $4 \mathrm{~mL} \mathrm{~min}^{-1} \mathrm{~g}^{-1}$. As noted, herein the GHSV was calculated as volumetric flow divided by catalyst mass. The concentration of the effluent gases $\left(\mathrm{C}_{2} \mathrm{H}_{2}, \mathrm{C}_{2} \mathrm{H}_{3} \mathrm{Cl}\right)$ were analyzed via a helium ion gas chromatography (GC-DID100) with a continuous discharge ionization detector. The long-term stability test was carried out at $\mathrm{T}=160{ }^{\circ} \mathrm{C}$ and total pressure of $0.3 \mathrm{Mpa}$ and GHSV $=10 \mathrm{~mL} \mathrm{~min}^{-1} \mathrm{~g}^{-1}$ with the initial content of $2000 \mathrm{ppm} \mathrm{C}_{2} \mathrm{H}_{2}$ balanced by $\mathrm{HCl}(>99.5 \%)$.

\section{Conclusions}

In present work, various types of low-mercury-supported catalysts (K-TX-O, K-WG-O, K-S20-O, $\mathrm{K}-\mathrm{S} 40-\mathrm{O}, \mathrm{K}-\mathrm{Fe} 0.8-\mathrm{O}, \mathrm{K}-\mathrm{Fe} 0.8-\mathrm{M}$ and $\mathrm{D}-\mathrm{Fe} 0.8-\mathrm{M}$ ) were prepared based on different types of active carbon substrates, which were further investigated for $\mathrm{C}_{2} \mathrm{H}_{2}$ abatement during highly purified $\mathrm{HCl}$ $(\mathrm{HP}-\mathrm{HCl})$ production process. It was revealed that the larger mesoporous volume of the catalyst samples, as well as $\mathrm{KCl}$ additive, constituted two main factors, which greatly influenced the catalytic activity and long-term stability of the catalysts samples. On one hand, the large mesopore volume of the catalyst sample facilitated better dispersions of the loaded $\mathrm{HgCl}_{2}$ species, which acted as the active 
centers during $\mathrm{C}_{2} \mathrm{H}_{2}$ catalytic abatement. On the other hand, the $\mathrm{KCl}$ additive not only could favor better dispersion of the $\mathrm{HgCl}_{2}$ species, but also could increase the adsorption stabilities of the loaded $\mathrm{HgCl}_{2}$ species. Based on present work, the sample of D-Fe0.8-M prepared by $\mathrm{KCl} / \mathrm{HgCl}_{2}$ step-by-step approach was proposed to be a promising candidate for $\mathrm{C}_{2} \mathrm{H}_{2}$ catalytic abatement, which exhibited higher $\mathrm{C}_{2} \mathrm{H}_{2}$ conversion activity and better long-term stability. In addition to that, the deactivation and reactivation of D-Fe0.8-M was further investigated. It was suggested that the $\mathrm{HgCl}_{2}$ loss and $\mathrm{C}_{2} \mathrm{H}_{3} \mathrm{Cl}$ accumulation constituted two main factors resulting in deactivation of D-Fe0.8-M; and the $\mathrm{HCl}$ treatment $\left(\mathrm{T}=220^{\circ} \mathrm{C}\right)$ could efficiently reactivate the deactivated sample, leading to the reactivated sample exhibiting similar catalytic activity and slightly lower lifetime $(t=190 \mathrm{~h})$ than that of the active sample of D-Fe0.8-M $(t=220 \mathrm{~h})$. Therefore, the prepared sample of D-Fe0.8-M constituted a promising candidate for $\mathrm{C}_{2} \mathrm{H}_{2}$ abatement during $\mathrm{HP}-\mathrm{HCl}$ production.

Supplementary Materials: The following are available online at http:/ /www.mdpi.com/2073-4344/8/12/610/s1. Figure S1. Pore size distributions of the AC substrates: (a) TX-AC (b) S20-AC (c) S40-AC (d) Fe0.8-AC (e) WG-AC; Figure S2. SEM images of the AC substrates: (a) TX-AC (b) S20-AC (c) S40-AC (d) Fe0.8-AC (e) WG-AC; Figure S3. XRD patterns of the substrates of Fe0.8-AC and S40-AC; Figure S4. EDS element analysis for the sample of ZS-SD1-Fe0.8-M, treated by $\mathrm{HCl}$ at $\mathrm{T}=220^{\circ} \mathrm{C}$ for $60 \mathrm{~h}$; Table S1. Elementary composition of the carbon powder (TX and HM); Table S2. Structure parameters of the AC substrates based on N2 adsorption/desorption.

Author Contributions: B. Chen conceived and designed the experiments; L. Jiang performed the experiments; R. Xu and C. Dai contributed with catalyst characterization; N. Liu analyzed the data and modified the manuscript. J. Zhang administrated the project.

Funding: The research was funded by the National Natural Science Foundation of China (Major Program 91534201, No. 21476012 and 21571012) for the financial support.

Conflicts of Interest: The authors declare no conflict of interest.

\section{References}

1. Wolfgang, A. Future semiconductor material requirements and innovations as projected in the ITRS 2005 roadmap. Mater. Sci. Eng. B 2006, 134, 104-108.

2. Hitoshi, H.; Yasuaki, A.; Shoji, A.; Toru, O.; Wei, F.Q.; Manabu, S.; Kikuo, O. Chemical process of silicon epitaxial growth in a $\mathrm{SiHCl}_{3}-\mathrm{H}_{2}$ system. J. Cryst. Growth 1999, 207, 77-86.

3. Tanimoto, Y. Hydrogen Chloride Manufacturing Method. CN Patent 107848799A, 27 March 2018.

4. Tanimoto, Y. Hydrogen Chloride Manufacturing Method. CN Patent 107848798A, 27 March 2018.

5. Zhang, J.R. Method and System for Preparing Hydrogen Chloride Gas with Moisture Content below $10 \times 10^{-6}$. CN Patent 102838087A, 26 December 2012.

6. Zhang, J.R. Method and System for Preparing Anhydrous Hydrogen Chloride Gas. CN Patent 101774543A, 14 July 2010.

7. Zhang, J.R.; Song, W.M. Method for Preparing Electronic Grade Hydrogen Chloride. CN Patent 1511780, 14 July 2004.

8. Severin, P.J.; Poodt, G.J. Capacitance-Voltage Measurements with a Mercury-Silicon Diode. J. Electrochem. Soc. 1972, 119, 1384-1388. [CrossRef]

9. Lima, F.G.D.C.; Mescheder, U.; Katona, G.; Leiste, H.; Özel, E.; Müller, C. Influence of silicon doping type on the adhesion of seedless electrodeposited copper layers. Surf. Coat. Technol. 2018, 349, 208-216. [CrossRef]

10. Tsai, C.C.; Jan, H.R.; Huang, C.H. Influence of surfactant addition for the texture etching process on multi-crystalline silicon wafer. J. Chin. Inst. Eng. 2012, 35, 69-77. [CrossRef]

11. Dai, B.; Chen, K.; Wang, Y.; Kang, L.; Zhu, M. Boron and nitrogen doping in graphene for the catalysis of acetylene hydrochlorination. ACS Catal. 2015, 5, 2541-2547. [CrossRef]

12. Li, P.; Li, H.; Pan, X.; Kai, T.; Cui, T.T.; Ding, M.Z.; Bao, X.H. Catalytically active boron nitride in acetylene hydrochlorination. ACS Catal. 2017, 7, 8572-8577. [CrossRef]

13. Lin, R.; Kaiser, S.K.; Hauert, R.; Perezramirez, J. Descriptors for high-performance nitrogen-doped carbon catalysts in acetylene hydrochlorination. ACS Catal. 2018, 8, 1114-1121. [CrossRef]

14. Zhi, L.; Li, Y.; Tang, H.; Liu, H.; Pei, W. Deactivation mechanism of low-mercury catalyst for acetylene hydrochlorination. Chem. React. Eng. Technol. 2015, 31, 343-353. 
15. Xu, X.L.; He, H.H.; Zhao, J.; Wang, B.L.; Gu, S.C.; Li, X.N. The ligand coordination approach for improving the stability of low-mercury catalyst in the hydrochlorination of acetylene. Chin. J. Chem. Eng. 2017, 25, 1217-1221. [CrossRef]

16. Hutchings, G.J.; Haruta, M. A golden age of catalysis: A perspective. Appl. Catal. A 2005, 291, 2-5. [CrossRef]

17. Mitchenko, S.A.; Krasnyakova, T.V.; Mitchenko, R.S.; Korduban, A.N. Acetylene catalytic hydrochlorination over powder catalyst prepared by pre-milling of K2PtCl4 salt. J. Mol. Catal. A Chem. 2007, 275, 101-108. [CrossRef]

18. Hutchings, G.J. Gole catalysis in chemical processing. Catal. Today 2002, 72, 11-17. [CrossRef]

19. Oliver-Meseguer, J.; Domenech-Carbo, A.; Boronat, M.; Leyva-Perez, A.; Corma, A. Partial reduction and selective transfer of hydrogen chloride on catalytic gold nanoparticles. Angew. Chem. Int. Ed. 2017, 56, 6435-6439. [CrossRef]

20. Zhu, M.; Wang, Q.; Chen, K.; Wang, Y.; Huang, C.; Dai, H.; Yu, F.; Kang, L.; Dai, B. Development of a heterogeneous non-mercury catalyst for acetylene hydrochlorination. ACS Catal. 2015, 5, 5306-5316. [CrossRef]

21. Conte, M.; Davies, C.J.; Morgan, D.J.; Davies, T.E.; Elias, D.J.; Carley, A.F.; Johnston, P.; Hutchings, G.J. Aqua regia activated $\mathrm{Au} / \mathrm{C}$ catalysts for the hydrochlorination of acetylene. J. Catal. 2013, 297, 128-136. [CrossRef]

22. Zhou, K.; Jia, J.; Li, C.; Xu, H.; Zhou, J.; Luo, G.H.; Wei, F. Low content Au-based catalyst for hydrochlorination of $\mathrm{C}_{2} \mathrm{H}_{2}$ and its industrial scale-up for future PVC process. Green Chem. 2014, 17, 356-364. [CrossRef]

23. Wang, Y.J.; Tian, Y.; Zang, W.C.; Jian, X.D. Study on treatment and recycling of mercury from waste mercury catalysts in China. Procedia Environ. Sci. 2016, 31, 432-439. [CrossRef]

24. Chen, M.; Kui, X.; Liao, J.; Chen, X. Effects of Cd cocatalytic mechanism in maltielement catalytic system on performance of low-level mercury catalysts. Polyvinyl Chloride 2014, 42, $26-29$.

25. Xu, X.L.; Zhao, J.; Lu, C.S.; Zhang, T.T.; Di, X.X.; Gu, S.C.; Li, X.N. Improvement of the stability of Hg/AC catalysts by $\mathrm{CsCl}$ for the high-temperature hydrochlorination of acetylene. Chin. Chem. Lett. 2016, 27, 822-826. [CrossRef]

26. Zhou, Y.; Yang, Q.; Luo, Q.; Jiang, W.W. Preparation and optimization of a new-type low-mercury catalyst for hydrochlorination of acetylene. Appl. Chem. Ind. 2011, 40, 2147.

27. Dong, X.B.; Chao, S.L.; Wan, F.F.; Guan, Q.X.; Wang, G.C.; Li, W. Sulfur and nitrogen co-doped mesoporous carbon with enhanced performance for acetylene hydrochlorination. J. Catal. 2018, 359, 161-170. [CrossRef]

28. Liu, Z.; Ling, L.; Qiao, W.; Lu, C.; Dong, W.; Lang, L. Effects of various metals and their loading methods on the mesopore formation in pitch-based spherical activated carbon. Carbon 1999, 37, 1333-1335. [CrossRef]

29. Liu, Z.; Ling, L.; Qiao, W.; Liu, L. Preparation of pitch-based spherical activated carbon with developed mesopore by the aid of ferrocene. Carbon 1999, 37, 663-667. [CrossRef]

30. Lowell, S.; Shields, J.E.; Thomas, M.A.; Thommes, M. Characterization of Porous Solids and Powders: Surface Area, Pore Size and Density; Springer: Dordrecht, The Netherlands, 2005; Volume 16, p. 1620.

31. Zhu, X.; Yu, S.; Xu, K.; Zhang, Y.; Zhang, L.; Lou, G. Sustainable activated carbons from dead ginkgo leaves for supercapacitor electrode active materials. Chem. Eng. Sci. 2018, 181, 36-45. [CrossRef]

32. Wade, C.B.; Thurman, C.; Freas, W.; Student, J.; Matty, D.; Mohantya, D.K. Preparation and characterization of high efficiency modified activated carbon for the capture of mercury from flue gas in coal-fired power plants. Fuel Process. Technol. 2012, 97, 107-117. [CrossRef]

33. Xie, Y.C.; Yang, N.F.; Liu, Y.J.; Tang, Y.Q. Spontaneous dispersion of some active components onto the surfaces of carriers. Sci. China Ser. B 1983, 26, 337-350.

34. Jiang, L.; Chen, B.H.; Zhang, J.R.; Fu, J.Q. Effect of activated carbon pore size distribution on low-mercury catalyst performance for acetylene hydrochlorination. J. Chem. Ind. Eng. 2018, 69, 423-428.

35. Wood, J.; Alldrick, M.J.; Winterbottom, J.M. Diffuse reflectance infrared Fourier transform spectroscopy (DRIFTS) study of ethyne hydrogenation on $\mathrm{Pd} / \mathrm{Al}_{2} \mathrm{O}_{3}$. Catal. Today 2007, 128, 52-62. [CrossRef]

36. Wei, H.; William, P.; Raul, F.L. Selective hydrogenation of acetylene in the presence of ethylene on K+- $\beta$-zeolite supported Pd and Pd/Ag catalysts. J. Catal. 2007, 246, 40-51.

(C) 2018 by the authors. Licensee MDPI, Basel, Switzerland. This article is an open access article distributed under the terms and conditions of the Creative Commons Attribution (CC BY) license (http:/ / creativecommons.org/licenses/by/4.0/). 